\title{
ESTUDIO DE ALGUNOS MATERIALES PICTORICOS UTILIZADOS POR ZUCCARO EN LAS OBRAS DE SAN LORENZO DE EL ESCORIAL
}

\author{
POR \\ ROCÍO BRUQUETAS GALÁN Y MARTA PRESA CUESTA \\ Int. ${ }^{\circ}$ Patrimonio \\ H. ${ }^{\mathrm{co}}$ Español \\ Fac. Bellas Artes \\ Complutense
}

\begin{abstract}
Three envelopes containing blue powdered pigments for painting were found in the general archives of Simancas, Spain. An investigation revealed that these materials could be related to two letters sent by $\mathrm{Fe}$ derico Zuccaro to Venice in which he ordered colours and brushes he would need for his work at the monastery of San Lorenzo de El Escorial. It was concluded that these pigments were showpieces used to define the desired quality of the colours. In this work, the content of the letters is commented and the pigments analysed, yielding ultramarine blue and smalt. This is followed by a review of the Spanish and Italian technical literature of that period in order to understand why Zuccaro needed to import some products from Venice. Finally, the transcription of the letters studied in this work is presented in appendix.
\end{abstract}

El presente trabajo se inició a raíz de un curioso hallazgo que tuvo lugar en el Archivo General de Simancas; curioso pues no se trataba esta vez de ningún documento escrito, sino de unos sobrecitos que contenían pigmentos azules para pintar. Se encontraban en el interior del Legajo 1538 de la Secretaría de Estado, entre los folios 226 y 227. Y aparecían envueltos en un papel en el que se leía la siguiente nota (Fig. 1):

\section{qui so le mostre una dal azuro oltramarino piu carico / e piu bello che si desidera $£ 1$ laltro del smalto da morano / per il frescho

Esta envoltura concretamente guardaba en su interior tres "papelillos» o sobrecitos de reducidas dimensiones, cada uno con una pequeña cantidad de pigmento. Dos de los papelillos tenían, a su vez, unas anotaciones. En el más grande se lee, en el exterior: s/mallto di morano scuro / per fresco $£ 50$ y, en su interior: di questa sorte [...] di colori / si disidera e non del piu ciaro che non / ne fa bisogno. En el exterior del segundo paquetito aparece anotado: oltramarino scuro / di questa sorta $£$ 1. El último de los sobrecitos, como ya se ha dicho, no presenta ninguna inscripción.

Investigando entre los documentos de éste mismo legajo, para dar una explicación a este hallazgo, se localizaron dos cartas del pintor Federico Zuccaro dirigidas al embajador de Felipe II en Venecia, Don Cristóbal de Salazar, con fecha de 1 de enero de 1586 y 17 de octubre del mis- 
mo año ${ }^{1}$. Estas cartas guardan relación directa con el contenido del paquete, pues la primera de ellas incluye una lista de colores y pinceles que solicita el pintor para iniciar los trabajos que le habían sido encomendados. Entre otros materiales, pide, conforme alla mostra, el mismo tipo y cantidad de azul de ultramar y de esmalte que la señalada en el envoltorio de los pigmentos, con la misma letra y tinta. De estos datos se deduce que Zuccaro pensaba enviar esos colores como muestra con el fin de que se adquirieran otros de calidad similar en Venecia.

La gestión quedó también reflejada en otros documentos, concretamente en tres listas de pedido de pinceles y colores, prácticamente idénticas a la incluida en la primera carta de Zuccaro ${ }^{2}$, y firmadas por fray Antonio de Villacastín, Obrero Mayor de la Congregación de El Escorial. Uno de estos documentos contiene también una carta de fray Antonio dirigida a Cristobal de Salazar, fechada en Valencia a 10 de febrero de 1586, pidiéndole que se haga cargo de comprar los colores con parecer de la persona a quien sobre lo mismo scrive el Pintor Federico Zucca$r o^{3}$.

Si se considera que los pigmentos que normalmente se analizan proceden de capas de pintura y se encuentran mezclados con otros materiales, fácilmente se explica lo insólito de este hallazgo que nos ha brindado la oportunidad de estudiar dos de los azules mas importantes del Renacimiento antes de su uso, tal y como se presentaban a la venta. La fortuna ha hecho que igualmente se hayan conservado los documentos que aclaran el origen y finalidad de los pigmentos. La posibilidad de estudiar en paralelo estos dos tipos de testimonios representa una oportunidad excepcional para la historia de los materiales pictóricos.

En las siguientes páginas, se da razón del contexto histórico y técnico que permite una mejor comprensión de los pedidos formulados por Zuccaro para, a continuación, contrastar los datos referentes a las categorías y calidades de los materiales requeridos con los resultados de los análisis de los pigmentos azules así como con otros documentos de la época.

\section{EL CONTEXTO HISTORICO}

En la primera carta, con fecha del 1 de enero de 1586, el pintor comenta haber llegado a San Lorenzo el Real hace quince días, de lo que se deduce que su llegada tuvo lugar el 15 de diciembre (Documento 1). Zuccaro había partido de Roma en viaje hacia España el 16 de septiembre de 1585 , después de firmar el contrato en aquella ciudad en agosto de ese mismo año ${ }^{4}$. En esta carta dice también que tuvo su primer encuentro con el rey en Monzón, donde por esas fechas se celebraban cortes, y allí mismo le ordenó lo que debía de hacer a su llegada al Monasterio.

Por tanto, Zuccaro hace su primera petición de pigmentos y pinceles a los pocos días de su llegada a El Escorial, ante la necesidad de proveerse de materiales para sus encargos. Como se sabe, este era un momento de gran actividad pictórica en el Monasterio, principalmente obras al fresco, y el gasto de materiales debió de ser grande. En septiembre, empezaban Nicolás Granello y Oracio Cambiaso la bóveda de la pieza del capítulo y del zaguán, y en diciembre, junto con Fabricio Castello se obligan a pintar la bóveda de las salas capitulares; en ese mismo mes, Rómulo Cincinnato está pintando el coro, comenzado por Luca Cambiaso.

\footnotetext{
1 A.G.S., Estado, Leg. 1538, fols. 364, 365 y 366.

2 A.G.S., Estado, Leg. 1538, fol. 341, Leg. 1537, fol 398 y Leg. 1342, fol. 11.

3 A.G.S., Estado, Leg. 1342, fol. 11. Transcrito y comentado por Mulcahy, R., «Federico Zuccaro and Philip II: the Reliquary altars for the Basilica of San Lorenzo de El Escorial", Burlington Magazine, 1987, CXXIX, pp. 502-509, nota n. ${ }^{\circ} 18$.

${ }_{4}$ Cloulas, A., "Les peintures du grand retable au Monastère de L'Escurial», Mélanges de la Casa Velázquez, 1966, t. IV, pp. 173-202.
} 
Los primeros encargos que Zuccaro recibió fueron los altares de las reliquias de la basílica y las pinturas murales del claustro. Empieza inmediatamente los altares, en los que trabaja durante casi todo el año, para darlos por finalizados, como él mismo indica en su segunda carta, el 10 de agosto, festividad de San Lorenzo y fecha elegida para la bendición de la iglesia. En esta carta, con fecha de 17 de octubre, dice que ya ha empezado los lienzos del retablo mayor (Documento 2).

Las pinturas murales del claustro, iniciadas en enero a la vez que los altares de las reliquias, las dejó desde un principio en manos de sus oficiales Bartolomé Carducho, Antonio de Ancona (Antonio Ricci), Tiberio Ronchi y Bernardino Veneziano ${ }^{5}$. Es bien conocida la mala acogida que tuvieron estas pinturas, pues, habiendo realizado solamente seis estaciones, son despedidos los ayudantes y se llama a Peregrino Tibaldi para que las continúe. Como tantas veces se ha dicho, a pesar del fausto recibimiento y del generoso salario que se le concedió, la pintura de Zuccaro, de una manera seca y poco apacible a decir del padre Sigüenza ${ }^{6}$, no satisfizo al rey y todas sus obras tuvieron escasa fortuna. Parte de los lienzos que el pintor hizo para el retablo mayor fueron sustituidos posteriormente por otros de Peregnno Tibaldi. Los que quedaron fueron retocados por el pintor Juan Gómez al igual que los altares de las reliquias. Sin embargo, Zuccaro expresa con orgullo en la segunda carta que fu tanto magiore il gusto di $\mathrm{Sm}^{\text {ta }}$ che alla partita sua di qui l'altra matina per madril, mi dono mille schudi d'oro, di moneda. Ciertamente, el trato que se le dió durante su estancia en España puede considerarse privilegiado a juzgar, no sólo por su salario, sino por las concesiones de que fue objeto.

Una de ellas es, sin lugar a dudas, la facilidad con la que se le proporcionaba el azul de ultramar. En nuestro país se utilizaba poco este pigmento ya que había que importarlo y resultaba excesivamente costoso, como luego se verá ${ }^{7}$. De hecho, en el caso de las obras reales, la primera vez que se tiene constancia de una petición de azul de ultramar procedente de Italia es en una carta de Don Juan de Idiáquez a Cristóbal de Salazar, fechada en San Lorenzo el 23 de septiembre de 1584, en la que le pide una serie de pigmentos y pinceles contenidos en una memoria firmada por Fray Antonio de Villacastín para las obras de El Escorial. Curiosamente, en esta carta se indica que para que la compra se açierte mejor os valdreys para fazella de personas confidentes que lo entiendan y si como en la memoria se dize federico zucaro no fuere partido para aca paresce que sera él el que mejor lo sabra hazer que nadie 8 .

Era una norma usual que la selección y compra de pigmentos se encomendara a un pintor de experiencia con el fin de acertar en las calidades y evitar las adulteraciones tan frecuentes. También otros pintores italianos contratados para las obras reales de Felipe II tuvieron el mismo encargo antes de su partida hacia España, como es el caso de Luca Cambiaso ${ }^{9}$. Incluso a Tiziano se le encargó en varias ocasiones la compra de algunos pigmentos, la primera vez, según los documentos, en $1551^{10}$. Se sabe, asimismo, que Tintoretto y Jerónimo Sánchez, hermano del pintor Sánchez Coello, actuaron como intermediarios reales en Italia para la selección de colores ${ }^{11}$.

\footnotetext{
5 Zarco Cuevas, J, Pintores italianos en San Lorenzo de E1 Escorial, Madrid, 1932.

${ }^{6}$ Sigüenza, J. de, La fundación del Monasterio de El Escorial, Madrid, 1605. Ed. Madrid, 1963, p. 476.

7 Las palabras de Pacheco sobre la utilización de este pigmento son muy ilustrativas, cuando dice que este azul "ni se usa en España ni tienen los pintores della caudal para usarlo» (Pacheco, F., El Arte de la Pintura, Sevilla, 1649, Ed. Madrid, 1990, p. 485).

8 A.G.S., Estado, Leg. 1340, fols. 83, 101-104.

9 López Torrijos, L., "Documentos genoveses para la venida de Luca Cambiaso a España", en Real Monasterio-Palacio de El Escorial, Estudios inéditos en el cuarto centenario de la terminación de las obras, Madrid, 1987, pp. 243-248.

10 A.G.S., Estado, Leg. 1565, fol. 91; cfr. Ferrarino, L., Tiziano e la Corte di Spagna nei documenti dell'archivio Generale di Simancas, Madrid, 1975, p. 136.

11 A.G.S., Estado, Leg. 1516, fol. 163; cfr. Mulcahy, R., «En la sombra de Alonso Sánchez Coello: la búsqueda de Jerónimo Sánchez", Archivo Español de Arte, 1990, pp. 304-309.
} 
Venecia era, en el siglo xvi, un importante centro de producción y comercio de colores debido al auge adquirido en la industria tintórea. Aquí llegaban minerales diversos y piedras semipreciosas como el lapislázuli, este último procedente de las minas de Afganistán y transportado a través de la ruta de la seda hasta el puerto de San Juan de Acre, en Palestina, en donde lo embarcaban los venecianos, monopolizándo casi por completo su comercio a partir de la Edad Media. También traían de Oriente colorantes vegetales y animales, resinas y gomas exóticas y productos químicos auxiliares con los que preparaban tintes, lacas y barnices. Los venecianos fabricaban sus propios pigmentos, como el esmalte y el giallolino de Murano -relacionados ambos con su importante industria vidriera- y otros como el cardenillo, el famoso albayalde de Venecia o sus celebradas lacas rojas. Todos estos materiales se preparaban y refinaban en esta ciudad para ser después distribuidos por toda Europa ${ }^{12}$.

La provisión de los mejores pigmentos para las pinturas de las obras reales fue una preocupación constante en el reinado de Felipe II. Ya en los primeros años se conocen encargos de colores a Flandes y a Italia con este motivo, destinados principalmente a las obras del Alcázar de Madrid, el Palacio del Pardo, el Bosque de Segovia y, más tarde, El Escorial. En la correspondencia diplomática con los embajadores de Venecia y Génova, o con el Cardenal Granvela en Flandes, aparecen a menudo memorias o peticiones de materiales con cantidades y precios, en las que generalmente se especifica que sean para pintar al fresco o al óleo, y se aconseja que sea una persona del oficio quien se encargue de comprarlos.

En esta ocasión, Zuccaro recomienda que sea el pintor Giovan Mario Verdi Zotti quien se encargue de buscar el azul de ultramar, ya que este personaje era, según sus palabras, molto intendente di tuto quello che ne fa bisognio, e qualuque religioso o de la profesione, o sol fare di quisto azuro oltramarino. Este pintor, especializado en género paisajístico, es conocido sobre todo por su labor literaria como poeta y por su amistad con Tiziano, resaltada por Vasari, Stringa, Baldinucci y otros autores ${ }^{13}$. De su vida sabemos que entra en el círculo de Tiziano, como su discípulo, a principios de 1556 y permanece en su taller hasta la muerte del maestro en 1576. Ejerció también las funciones de secretario -como hizo anteriormente Aretino-, escribiendo las cartas que Tiziano dirigía a los reyes de España y otras personalidades ${ }^{14}$. Respecto a su pintura, los críticos no aportan demasiados datos -únicamente resaltan su afición al género paisajístico, en donde refleja la influencia de Tiziano-, ya que no era pintor de profesión, sino que compaginaba esta actividad con la poesía y sus labores de religioso. Venturini se hace eco de una opinión generalizada entre los críticos sobre la probable autoría de Verdi Zotti de la primera biografía de Tiziano, Vita dell'insigne pittore Tiziano Vezellio (Venecia, 1622), de autor anónimo ${ }^{15}$.

Igualmente, intervinieron en la compra de estos colores los pintores Andrea Vicentino y el Maestro Rocco. El primero era un pintor colorista de influencia veronesa, considerado por Ridolfi y los contemporáneos como un autodidacta, un practicon de man por excelencia, volcado

12 Lazzarini, L., "Il colore nei pittori veneziani tra il 1480 e il 1580 ", Studi veneziani, suplemento n. ${ }^{\circ} 5$ del Bollettino d'Arte, Roma, 1983, pp. 137 y ss.

13 Vasari, G., Vidas de artistas ilustres completas, Barcelona, 1957, t. V, p. 259. El escritor conoció personalmente a Verdi Zotti en el estudio de Tiziano y lo llama "gentilhombre veneciano». Stringa, G., Venetia Città Nobilissima et singolare Descrita gia in XIIII Libri da M. Francesco Sansovino, hora corretta emendata ... dal M.R.D. Giovanni Stringa, Venecia, 1604. Dolce, L., Dialogo della Pittura, Venecia, 1557. Ridolfi, Delle maraviglie dell'arte overo vite degli illustri pittori veneti, Venecia, 1648. Baldinucci, F., Notizie dei professori del disegno, Florencia, 1681. Ed. Florencia, 1975, p. 574.

14 Venturini, G., "Giovanni Mario Verdi Zotti, pittore e incisore, amico e discepolo del Tiziano", Bollettino del Museo Civico de Padova, 1970, LIX, pp. 33-73. Venturini, G., Cinquecento minore. O. Ariosto, G. M. Verdi Zotti e il loro influs so nella vita nell'opera del Tasso, Rávena, 1970. Tiziano, le lettere. Dalla sillogie dei documenti tichianesqui di Celso Fabro, Cadore, s.f. Petrocchi, "Scrittori e poeti nella bottega di Tiziano", en Tiziano e Venezia, Convegno Internazionale di Studi, Venecia, 1976. Hochmann, M., Peintres et commanditaires à Venise, 1540-1628, Roma, 1992.

15 Venturini, G., op. cit., pp. 33-73. 
hacia la mancha y el color y con escasa atención hacia el dibujo ${ }^{16}$. Del Maestro Rocco se conocen menos datos y podría tratarse de Rocco de San Silvestro, calificado por Baldinucci como ordinario pittore ${ }^{17}$.

Habría que destacar también la relación de amistad que parece unir a Zuccaro con Paolo Veronés, pues en la carta del 17 de octubre menciona otra que envía adjunta a este pintor y a otros conocidos suyos, como el Patriarca Grimani o el escultor y estuquero Alessandro Vittoria, ayudante de Sansovino, para que se deleiten con sus impresiones sobre El Escorial, Aranjuez y Toledo. Conocida es la afición literaria y epistolar de Zuccaro a través de las cartas que envió a sus amistades, en las que describe los lugares que visitó en sus viajes ${ }^{18}$.

\section{LOS MATERIALES PEDIDOS POR ZUCCARO A VENECIA}

Federico Zuccaro vino a España provisto de pequeñas cantidades de los pigmentos más finos, ya que el 14 de febrero de 1586, fecha próxima a su llegada, el Monasterio le paga cierta cantidad de dinero por las colores [...] que del se compraron y recivieron para las pinturas que se hazen en la dicha fabrica ${ }^{19}$. Es muy interesante la relación de colores que se citan, pues en ella se puede ver la gran variedad de "suertes» de azul de ultramar que existía en el mercado -hasta trece clases distintas - todas ellas con sus diferentes precios. La amplia gama de pigmentos y las pequeñas cantidades de ellos que figuran en el listado sugieren que pudiera tratarse de un muestrario de los mejores colores. Es muy posible que, a la vista de la importancia de los trabajos que le habían sido encomendados, Zuccaro utilizara parte de estas muestras como patrón de calidad para pedir a Venecia las «suertes» de colores que necesitaba.

\section{El azul de ultramar}

El principal interés del artista fue, sin ninguna duda, conseguir mayor cantidad de azul de ultramar ya que, como indica en su primera carta, qua ve ne molto pocho, e l'opera e molta. En la lista de le cose che qui faltano incluye cuatro tipos de azul de ultramar: 1 libra del más fino, piu bello e carico di colore, que costaba entre veinte y veinticinco escudos la onza; otra libra de un azul de ultramar algo más corriente, bello, pero ya comercializado a la mitad del precio del más fino; dos libras de la calidad inferior, del piu baso, vendido entre tres y cuatro escudos la onza; y, finalmente, seis libras de las llamadas cenizas de ultramar, las cuales costaban entre medio y un escudo la onza.

Obtener la mejor variedad de ultramar preocupaba tanto a Zuccaro que en su carta recomienda confiar el encargo al ya mencionado Verdi Zotti, quien no sólo entendía en la compra del ultramar sino que además lo elaboraba él mismo y ya se lo había proporcionado al pintor en otras ocasiones: e sol fare di quisto azuro oltramarino, et altre volte ne o avuto da lui del belis[si]mo. La selección debía hacerse, en todo caso, según la mostra che si manda.

16 Donzelli, C., Pilo, G. M., I pittori dei seicento veneto, Florencia, p. 418.

17 Baldinucci, op. cit., p. 566.

18 Heikamp, D., «I viaggi di Fedenco Zuccari», Paragone, IX, 1958, n. ${ }^{\circ}$ 105, Domínguez Bordona, J, «Federico Zuccaro en España", Archivo Español de Arte y Arqueología, 1927, pp. 81-89, y Pérez Sánchez, A., "Céspedes de Guadalupe", Archivo Español de Arte, 1971, n. ${ }^{\circ}$ 175, pp. 338-341.

19 Archivo de la Real Biblioteca de El Escorial, 1586, 10-12, cfr. Zarco Cuevas, J., Pintores españoles en San Lorenzo de El Escorial (1566-1613), Madrid, 1931, p. 257. 
Las precauciones de Zuccaro no eran vanas, ya que el azul de ultramar natural se extraía de la piedra semipreciosa llamada lapislázuli ${ }^{20}$, y la calidad del azul obtenido podía ser muy variable. Fundamentalmente, dependía de la bondad inicial del lapislázuli, es decir, de su riqueza en el mineral azul -la lazurita- ${ }^{21}$, del proceso de purificación empleado y de la habilidad del operario que lo llevara a cabo.

El método de purificación, consagrado por la práctica medieval y detalladamente descrito por Cennino Cennini, consiste en incorporar el polvo de lapislázuli en una mezcla de resinas, cera y aceite llamada "pastel», aglomerado que, tras un tiempo de reposo, se amasa en agua templada o, más frecuentemente, en una lejía suave. De este modo se libera gradualmente el polvo del lapislázuli, comenzando por las fracciones más gruesas y azules, mientras el resto de los constituyentes de la piedra - principalmente partículas de calcita y de pirita- quedan retenidos en el pastel en su mayor parte. La base científica de este método de purificación aún no ha sido completamente explicada. Aparentemente se trata de un mecanismo en su mayor parte físico, regido por la capacidad que tiene el "pastel" para humectar y adherir las impurezas, a la par que su escasa afinidad por la lazurita permite el paso del mineral al agua o lejía ${ }^{22}$. Según indica J.-F.-L. Mérimée, el proceso se ve favorecido por la fermentación de la pasta ${ }^{23}$. Una vez suficientemente coloreado el líquido de extracción, se vierte en otro recipiente y, añadiendo una nueva porción de lejía, se continúa amasando el pastel. La operación se repite hasta extraer la mayor parte del azul y las distintas fracciones de líquido coloreado se dejan decantar, se vierte fuera el líquido, se lava el poso azul y se deja secar. Como puede suponerse, la calidad del pigmento obtenido en la primera extracción es la mejor y va decreciendo en las sucesivas operaciones, ya que el tono se va apagando debido a la presencia de impurezas como la calcita.

Alessio Piemontese, en su obra De’ Secreti, incluye dos recetas muy detalladas para la preparación del ultramar dirigidas especialmente a fabricantes y comerciantes ${ }^{24}$. Describe cómo reconocer el mejor lapislázuli, la forma de triturarlo y de molerlo, la manera de preparar distintos "pasteles», etc. Indica, por ejemplo, que el lapislázuli finissimo e perfetto podía llegar a pagarse trece o catorce escudos la onza, pero advierte que de esta calidad se ne ritrova poco, y más adelante afirma que la habitual en el mercado costaba entre seis y ocho escudos la libra ${ }^{25}$. Al final, si la piedra era buona e fina y todo el proceso de extracción se lleva a cabo correctamente, se obtenían tres clases de azul de ultramar. Alessio Piemontese las describe como sigue:

«el primer azul, cuando sale, parece algo más grueso que los otros, y esto se debe a las venas del oro que hay en esta piedra ${ }^{26}$. El segundo parece más fino, pero no tiene un color tan bello. El tercero parece algo más fino, pero más pálido de color, y más abierto y claro, y esto se entiende cuando el

20 Desde principios del siglo XIX se produce artificialmente un compuesto muy similar a la lazurita conocido igualmente como azul de ultramar.

21 La lazurita es el principal componente del lapislázuli y el que le confiere su característico color azul. Es un silicato de sodio y aluminio con azufre, cuya composición ligeramente variable viene expresada por la fórmula $\mathrm{Na}_{8-10} \mathrm{Al}_{6} \mathrm{Si}_{6} \mathrm{O}_{24} \cdot \mathrm{S}_{2 \pm}$. No hay que confundir la lazurita con otros minerales azules y con un nombre similar como son la azurita, $2 \mathrm{CuCO}_{3} \cdot \mathrm{Cu}(\mathrm{OH})_{2}$, y la lazulita, $\mathrm{MgAl}_{2}\left(\mathrm{PO}_{4}\right)_{2}(\mathrm{OH})_{2}$ (Heinrich, E. W., Identificación microscópica de los minerales, Bilbao, 1979, pp. 87-88 y 168-169, y Gettens, R. J. y Fitzhugh, E. W., "Azurite and Blue Verditer", en Artists' Pigments, vol. 2, Oxford, etc., 1986, p. 23).

22 Plesters, J., "Ultramarine Blue, Natural and Artificial», en Artists' Pigments, vol. 2, Oxford, etc., 1986, p. 39.

23 Mérimée, J.-F.-L., De la peinture à l'huile, París, 1830. Ed. Puteaux, 1981, p. 180.

24 Piemontese, A., De' Secreti del Reverendo Donno Alessio Piemontese, Venecia, 1555. Ed. Venecia, 1663-1670, Parte I, pp. 55-56, Parte II, pp. 30-34.

25 Piemontese, A., op. cit., Parte II, pp. 32 y 34.

26 En realidad, se trata de pirita y no de oro. 
lapislázuli es bueno y perfecto. [...] y si la piedra fuera de la buena y fina, obtendrás, contando cada cosa, al menos diez onzas y media, y si no fuera tan fina, al menos ocho onzas, y ten en cuenta que la piedra podría ser tan miserable, que no obtendrías ganancias, sino que con ella perderías» ${ }^{27}$.

Apurando la extracción del azul al máximo, al final se obtienen las cenizas -cinerario-, con muchas impurezas y muy poca lazurita, de las cuales se ne fa poco conto, pure alcuna volta ti pagarà la spesa del pastello ${ }^{28}$. Por lo tanto, finalizado el proceso, lo normal era haber conseguido tres clases de azul y, eventualmente, una de cenizas, precisamente las clases que Zuccaro pide a Venecia.

La fortuna ha querido que llegue hasta nosotros, conservada en el Archivo General de Simancas, una muestra del oltramarino scuro, del piu bello e carico di colore da venti e venticinque schudi l'oncia, es decir, de una de las mejores calidades de azul disponibles en la época. Los estudios en laboratorio han determinado que, efectivamente, se trata de azul de ultramar natural. El análisis elemental por fluorescencia de rayos $\mathrm{X}$ ha puesto en evidencia la presencia de $\mathrm{Na}, \mathrm{Al}, \mathrm{Si}$ y S que caracterizan a la lazurita ${ }^{29}$, así como de cierta cantidad de Ca procedente de la calcita también presente en el lapislázuli.

Una pequeña parte de la muestra fue montada para su estudio al microscopio óptico y posterior análisis de imagen por ordenador. De esta forma, sobre una muestra de alrededor de un millar de partículas, pudo comprobarse que los fragmentos de lazurita estaban acompañados por otros blancos muy birrefringentes de calcita, presentes en una proporción del $27 \%$ en volumen. Las partículas de lazurita son angulosas y de tamaño muy variado, con un diámetro medio del disco equivalente de $13 \mu \mathrm{m}$ y una desviación estándar de $17 \mu \mathrm{m}$. Por su parte, las partículas de calcita muestran características morfológicas muy similares, pero con una distribución de talla más estrecha ${ }^{30}$.

Aunque en las reproducciones modernas del procedimiento de purificación del ultramar ya se había constatado que la lazurita siempre se desprende junto con cierta cantidad de impurezas ${ }^{31}$, estos análisis demuestran que también el mejor azul de ultramar comercializado a finales del siglo xvI, supuestamente elaborado por artífices experimentados, contenía una alta proporción de calcita.

Los análisis de laboratorio también han permitido la identificación de la muestra de azul sin etiquetar contenida en el paquetito más pequeño de los tres conservados en el Archivo. Se trata igualmente de azul de ultramar natural, de una calidad muy similar al anterior 32.

Gracias a la lista de colores que Zuccaro pide a Venecia en esta ocasion y a otros documentos conservados en el Archivo General de Sirnancas y en el Archivo de la Real Biblioteca de El Escorial, podemos conocer los precios de las distintas variedades de azul de ultramar que llegaban a España entre 1585 y 1586. Las variedades más bajas costaban entre 3 y 10 escudos la onza y las mejores, llamadas açul finissimo hultramarino, entre 24 y 30 escudos de oro la onza,

27 Piemontese, A., op. cit., Parte II, pp. 33-34. Para su mejor comprensión nos hemos permitido traducir la cita.

28 Piemontese, A., op. cit., Parte II, p. 32.

29 Ver nota n. ${ }^{\circ} 21$.

30 Existen varios procedimientos para caracterizar el tamaño de una partícula y, entre ellos, uno de los más usados es el del diámetro del disco equivalente, es decir, el del diámetro del disco cuyo área es igual al área de la partícula proyectada sobre una superficie (Connor, M., Consolidation mechanisms and interfacial phenomena in thermoplastic powder impregnated composites, thèse n. ${ }^{\circ} 1413$ (1995), Escuela Politécnica Federal de Lausana, p. 19). La micra ( $\left.\mu \mathrm{m}\right)$ es la milésima parte del milímetro.

31 En los análisis de azul de ultramar procedente de obras de distintas épocas también se han encontrado importantes cantidades de calcita (Plesters, J., op cit., p. 39 y 43).

32 Con una proporción lazurita/calcita de aproximadamente el $28 \%$. La menor cantidad de muestra disponible ha hecho que el cálculo de distribución lazurita/calcita sea algo menos fiable que en el caso anterior. 
como el que a su llegada a España se le pagó a Zuccaro ${ }^{33}$. Los treinta escudos que costaba una onza -es decir, alrededor de 28 gramos- del mejor azul de ultramar equivalían a unos 10.500 maravedís, cantidad superior al salario mensual de un pintor de la corte como, por ejemplo, Nicolás Granello, mientras que el esmalte, el otro azul pedido por Zuccaro a Venecia, costaba en 1585 alrededor de 2.800 maravedís la libra o, lo que es lo mismo, 175 maravedís la onza -60 veces menos que el mejor ultramar- ${ }^{34}$.

\section{El esmalte de Murano}

El tercer pigmento azul analizado procede del mayor de los paquetitos, etiquetado como s[mallto di morano scuro per fresco. $\mathrm{Al}$ igual que en el caso del mejor azul de ultramar, Zuccaro envía una muestra para orientar la compra. A simple vista, se trata de un azul de color más intenso que el de las otras dos muestras. Sin embargo, bajo el microscopio óptico se observan unos fragmentos de color más bien pálido, angulosos, de un tamaño medio tres veces superior al de las partículas de lazurita ${ }^{35}$, y con algunas microburbujas incluidas en su masa, detalle característico de las pastas de vidrio. Según dichas observaciones, el azul contenido en esta última muestra es el llamado esmalte, tal como indican la etiqueta y la lista de pedido de materiales enviada por Zuccaro a Venecia. Los análisis por fluorescencia de rayos X confirman esta identificación al poner de manifiesto la presencia de los elementos constitutivos del vidrio ( $\mathrm{Si}, \mathrm{K}$ y $\mathrm{Ca}$ ) y de la materia colorante (Co), además de cantidades importantes de otros elementos ( $\mathrm{As}, \mathrm{Fe}$ y $\mathrm{Ni}$ ).

El esmalte es un vidrio azul coloreado con óxido de cobalto. Su utilización en la pintura europea, según los datos disponibles actualmente, se inicia en la segunda mitad del siglo xv, aunque su empleo no se hizo frecuente hasta bien entrado el siglo XVI ${ }^{36}$. Sin embargo, los orígenes de este pigmento son poco conocidos y, en general, la historia del uso de los minerales de cobalto como materia colorante para fabricar vidrios azules presenta aún bastantes lagunas.

Entre las fuentes estudiadas, sólo hemos podido encontrar una receta para la fabricación del esmalte azul perteneciente a la tradición vidriera muranesa. El texto aparece dentro del recetario escrito entre el 1644 y el 1654 por el vidriero Giovanni Darduin, pero pertenece al grupo de instrucciones que el autor transcribe y comenta a partir de las notas de su padre Nicolò, activo durante el último tercio del siglo XvI ${ }^{37}$.

Desde el punto de vista de nuestro estudio, la receta de Nicolò Darduin para fabricar esmalte tiene una importancia especial puesto que corresponde exactamente con el pigmento solicitado por Zuccaro -un esmalte de Murano para fresco- y con la época de dicha petición ${ }^{38}$. Ade-

33 Zarco Cuevas, J., op. cit., p. 257.

34 También la diferencia de precio con respecto a otros colores era grandísima. El carmín de Florencia, pigmento que igualmente resultaba muy caro, podía llegar a costar por esos años unos 350 maravedís la onza, es decir, aproximadamente lo mismo que las cenizas de ultramar, mientras que el azul de cenizas -la mejor variedad de azul de azurita- salía a unos 51 maravedís la onza y el albayalde común, uno de los colores más baratos, costaba en 1588 unos 25 maravedís la onza.

35 Sobre una población de 56 partículas, el diámetro del disco equivalente varía entre 6 y $80 \mu \mathrm{m}$ con un tamaño medio de $38 \mu \mathrm{m}$ y una desviación estándar de $17 \mu \mathrm{m}$; ver nota n. ${ }^{\circ} 30$.

36 Mühlethaler, B., Thissen, J., "Smalt", en Artists' Pigments, vol. 2, Oxford, etc., 1993, pp. 113-130.

37 Según las investigaciones de L. Zecchin en las Actas parroquiales de S. Stefano, actualmente en el Archivio di S. Pietro Martine, se menciona que Nicolò Darduin nace en 1546 y muere en 1599. Giovanni fue el octavo de sus hijos, nacido en 1585, comienza su recetario a los cincuenta años presentándolo como: "Copie di tutti li secretti de smalti, cavate dalli Libri et altre Carte della buona memoria di mio padre, ridotte in questo Libro et registrate con ordine et regola" (Zecchin, L., et al., Il ricettario Darduin, un codice vetrario del Seicento trascritto e commentato, Venecia, 1986, p. 42 y 107).

38 Como ya se ha mencionado, las cartas de Zuccaro están fechadas en 1586 y la receta, aunque transcrita entre el 1644 y el 1654 por el vidriero muranés Giovanni Darduin, pertenece a las notas dejadas por su padre Nicolò, cuya vida se desarrolló entre el 1546 y el 1599 . 
más, al encontrarse dentro del cuaderno de notas de una familia de vidrieros venecianos, no puede cuestionarse lo representativo del procedimiento con respecto a la práctica muranesa de los siglos XVI y XVII ${ }^{39}$.

La receta del azul de esmalte dice lo siguiente:

"Como hacer esmalte para muro bello. Toma 300 libras de gripola negra del Friul, y 90 libras de quogolo del Ticino, y haz una frita a fuego suave. Después, toma 200 libras de esta frita y mézclala con 85 libras de zafaro que sea bueno y bien calcinado y colócalo [en el horno] a fuego fuerte durante un día y medio, y harás un bello color, y si además le agregaras un poco de manganese, algo así como libra y media o dos, no será malo. Ten en cuenta que si le añades otras 15 ó 20 libras de quogolo, además de las 90 libras ya empleadas para hacer la frita, podría salirte más bello» ${ }^{40}$.

Gripola o tartaro era el nombre que recibía el cremor tártaro -tartrato de potasio impuroque precipita en las cubas de fermentación del vino y se adhiere a sus paredes. Recogiendo y calcinando parcialmente este depósito se obtenía la gripola negra de la receta ${ }^{41}$. La calcinación transformaba el tartrato de potasio en carbonato de potasio bastante puro, el cual, empleado como fundente, daba lugar a vidrios potásicos. No obstante, hay que señalar que, tanto en el recetario Darduin como en otros recetarios venecianos de la época, normalmente la gripola sólo se utilizaba en pequeñas cantidades en la fabricacion de ciertos vidrios especiales, mientras que lo abundante en la producción muranesa fueron los vidrios sódicos, preparados empleando como fundente las cenizas de plantas litorales ricas en carbonato sódico ${ }^{42}$.

Los quogoli del río Ticino eran guijarros cuarcíferos muy limpios, con escasas impurezas colorantes. Durante siglos constituyeron el material vitrificante preferido en las vidrierías de Murano ${ }^{43}$.

Zafaro o zafre era el nombre con el que durante siglos se conocieron las distintas formas de comercializar los minerales de cobalto destinados a colorear vidrios. Este vocablo, de origen árabe, aparece ya en los documentos muraneses de mediados del siglo xv ${ }^{44}$.

Por último, el manganese mencionado en la receta era el bióxido de manganeso natural más o menos puro que, como materia colorante, se utilizaba sobre todo para obtener vidrios de color violeta ${ }^{45}$. Darduin señala que en la preparación del esmalte se podía añadir una pequeña cantidad de manganese para mejorar el color. Es probable que con esta adición el azul adquiriera una ligera tonalidad violácea que lo asemejara al color de los mejores azules de ultramar 46 .

Llevando a la práctica la receta de Nicolò Darduin se obtendría un vidrio potásico azul, co-

39 Según Rosa Barovier Mentasti se puede afirmar sin ninguna duda que entre los recetarios y libri di segreti de los siglos XV y XVI conservados, el recetario Darduin es el más importante, por tratarse de un auténtico instrumento de trabajo de un vidriero veneciano (Zecchin, L., et al., op. cit., p. 17).

40 Ms. Segreti per far lo smalto et vetri colorati, conocido como Ricettario Darduin, del Archivio di Stato de Venecia, en la "Miscellanea di Atti diversi: Manoscritti", serie 41, fol. 19 r. (Zecchin, L., et al., op. cit., p. 145, receta n. ${ }^{\circ}$ LXVIII). Para su mejor comprensión nos hemos permitido traducir la cita.

${ }^{41}$ Darduin describe el modo de calcinar el tártaro en la receta n. ${ }^{\circ}$ CIII: A calcinar il tartaro cioè la gripola (Zecchin, L. et al. op. cit., p. 166).

42 Zecchin, L., et al., op. cit., pp. 256-257.

43 Según las investigaciones de L. Zecchin, aparecen mencionados en los documentos venecianos desde el 1470 hasta finales del siglo xvill, (op. cit., p. 258). También el florentino A. Neri los menciona como el tipo de guijarros preferidos en Murano: "A Murano usano quocoli del Tesino, pietra abbondante nel fiume Tesino" (Neri, A., L'Arte Vetraria, Florencia, 1612, Ed. Milán, 1980, p. 4).

44 Neri, A., op. cit., p. XCVI; Darrah, J. A., "Connections and Coincidences: Three Pigments", en Historical Painting Techniques, Materials and Studio Practice, Leiden, 1995, p. 74.

45 Zecchin, L., et al., op. cit., p. 258.

46 Según algunos autores, los mejores esmaltes eran aquellos con un color próximo al del ultramar (Pemety, A.-J., Dictionnaire portatif de peinture, sculpture et gravure, París, 1757, Ed. Ginebra, 1972, p. 20). 
loreado con cobalto y, eventualmente, con algo de manganeso. Por otra parte, al ser las materias primas empleadas de origen natural, la presencia de ciertas impurezas resultaría inevitable.

La muestra de esmalte conservada en el Archivo General de Simancas es efectivamente, según los análisis ya comentados, un vidrio potásico coloreado con cobalto, pero sin el añadido del bióxido de manganeso para mejorar su color. Los resultados de laboratorio también han puesto en evidencia la presencia de importantes cantidades de arsénico, hierro y níquel. Dichos elementos proceden, sin ninguna duda, de las impurezas de la mena de cobalto utilizada. Durante siglos, los yacimientos de Sajonia fueron la principal fuente del cobalto empleado en Europa. Según la descripción de Beckmann, de allí se extraían menas complejas de Co-Ni-Fe-As ${ }^{47}$, lo cual se corresponde perfectamente con el mineral de cobalto empleado en la fabricacion del esmalte de Murano pedido por Zuccaro.

En definitiva, tanto la receta de Darduin como los análisis del esmalte pedido por Zuccaro, señalan que, al menos durante la segunda mitad del siglo xvI, no existía una diferencia notable entre la composición de los esmaltes producidos en Murano y la de los del norte de Europa, tanto en lo que se refiere a la mena de cobalto empleada como materia colorante como al tipo de vidrio obtenido, potásico en ambos casos, hecho notable si se tiene en cuenta que los contextos de producción eran distintos. Entre las diferencias técnicas más notables hay que señalar que en Venecia predominaba la producción de vidrios sódicos y en el norte de Europa la de vidrios potásicos y que, mientras la materia prima del potasio normalmente empleada en Murano era la grepola di vino, en el norte se usaban sobre todo las cenizas de plantas locales.

En cuanto a la calidad de la producción, los documentos indican que. aunque en este caso se solicita esmalte de Murano, los azules de este tipo más famosos eran los procedentes del Norte de Europa y, más concretamente, de Flandes. Paolo Lomazzo describe el esmalte flamenco como il migliore de gl'altri tutti ${ }^{48}$. La misma preferencia se refleja en algunas peticiones de colores para las obras reales y, así, en los primeros años del reinado de Felipe II, se trae esmalte de Flandes para las pinturas murales que estaba realizando Becerra en el Alcázar de Madrid y en el Palacio del Pardo. Un testimonio curioso es la carta que, el 17 de febrero de 1564, envía el cardenal Granvela al secretario Pedro de Hoyos haciendo referencia a un famoso fabricante de esmalte llamado Bernard. El fragmento que transcribimos a continuación revela la gran atención que se prestaba en la corte a la calidad de los pigmentos que se iban a emplear en las obras reales, para cuya selección y búsqueda no se dudaba en poner en marcha el aparato de Estado:

«Dicen estos pintores [los encargados de comprar los pigmentos] que no se halla mas del verdadero smalte de bernard porq[ue] él murió en Alemania y aunq[ue] su mujer lo contrahace no acierta como el marido, no obstante que los sacos vienen de hallá con la mesma marca q[ue] en t[iem]po del marido, pero hay tanta diferencia que si se hallasse agora del verdadero de bernard valdría a 20 flor[ine]s la libra y el mismo pintor de aquí de brusselas [...] ha escripto en Alemania para ver si allá se prodría hallar alguna quantidad del verdadero smalte de bernard. Dizen también estos pintores que es verdad que la mujer ha acertado alguna vez a hazer el smalte tan bueno como el marido y aún mejor, pero q[ue] ha sido rariss[im]as vezes" 49 .

\section{El blanco de plomo y los pinceles}

Volviendo a la lista de materiales solicitados por Zuccaro, vemos que, además de los distintos azules, el pedido incluye 300 libras de biacha o blanco de plomo y varios tipos de pinceles

\footnotetext{
47 Beckmann, J., A History of Inventions, Discoveries and Origins, 4th ed, London, 1846, citado por Mühlethaler, B., Thissen, J., op. cit., p. 113.

48 Lomazzo, G. P., Trattato dell'arte de la pittura, Milán, 1584. Ed. Hildesheim, 1968, p. 191.

49 A.G.S., Legajo 275, fols. 35 y 36. Citado por Checa, F., Felipe II, mecenas de las artes, Madrid, 1992, p. 138, nota 133.
} 
para pintar al óleo, pequeños, grandes y medianos, de varo y de setole, es decir, de pelo de ardilla y de cerdas ${ }^{50}$. Aunque estos materiales u otros similares eran corrientes en España, el interés de Zuccaro por traerlos de Italia se explica tanto por la fama que los productos de Venecia tenían por aquel entonces entre los pintores como por el deseo del artista, que como se ha visto tenía carta blanca, de trabajar en las mejores condiciones para Felipe II.

La biacha o biacca fabricada en Venecia en los siglos xvı y xvII debía de ser de una calidad especialmente refinada y de ello se hacen eco algunos pintores tratadistas, como es el caso del español Francisco Pacheco quien, en su famosa obra de El arte de la pintura, recomienda emplear el mejor albayalde [es decir, blanco de plomo] que se hallare, y lo es sobre todos el de Venecia, que muestra dureza y se quiebra como laxitas cortadas con cuchillo ${ }^{51}$. Precisamente, es esta configuración específica en laminillas o escamas muy blancas y fáciles de romper, la que también según otros autores caracteriza las calidades más finas de blanco de plomo. Por el contrario, las calidades corrientes del pigmento se vendían en forma de panes, eran de un blanco algo sucio y podían contener cierta cantidad de creta, por lo que, empleadas al óleo, amarilleaban enseguida ${ }^{52}$.

También los pinceles procedentes de Venecia tenian muy buena reputación a juzgar por las palabras de Giovan Battista Armenini, pintor y tratadista italiano coetáneo de Zuccaro:

"son los pinceles, como se sabe, de dos clases, de pelo de vaio y de cerdo ${ }^{53}$, estos se emplean al fresco, aquellos al óleo, y al secco, los cuales [pinceles de vaio] pocos artífices se los hacen, porque los hay que los venden para las tiendas y especierías, y entre los mejores se tiene a los que se traen de Venecia...." ${ }^{54}$.

En Italia existían, por lo tanto, dos tipos fundamentales de pinceles: los de vaio y los de cerdas ${ }^{55}$, los primeros especialmente indicados para la pintura al óleo y los segundos para la pintura al fresco. No obstante, la gama de pinceles disponible en la época era mucho más variada. Vicente Carducho, testigo directo durante su juventud de la actividad de Zuccaro en España, nos ha dejado una relación de los tipos de pelos más frecuentes en la elaboración de pinceles, y en ella se incluyen, además de los de ardilla y de cerdas, los de turón, meloncillo, cabra y perro. También describe sucintamente los diferentes montajes de los pelos finos en cañones de aves o de hoja de lata y de las cerdas atadas en astas, las cuales, solo se gastan en cosas grandes al olio, fresco y temple ${ }^{56}$.

\footnotetext{
50 La voz véneta 'varo'suele ser traducida al español como 'marta', pero, según F. Brunello, ésta palabra quiere decir 'scoiattolo' (Sciurus vulgaris), es decir, 'ardilla'. En otras partes de Italia, el término comúnmente empleado para designar ese mismo material fue el de 'vaio'(Cennini, C., Il libro del arte. Ed. Vicenza, 1992, p. 12, nota n. $\left.{ }^{\circ} 4\right)$.

51 Pacheco, F., op. cit., p. 483.

52 De Mayeme, T. T., Pictoria, Sculptoria et quae subalternarum artium, 1620, Ms. del British Museum, Sloane n. ${ }^{\circ}$ 2052, fols. 11 y 88 . Ed. Lyon, s.f., pp. 26 y 104, y Pernety, A.-J., op cit, pp. 30 y 51-52. La diferencia de calidad entre el blanco de plomo común y el blanco de plomo en escamas se debía a ciertas modificaciones en el proceso de fabricación del pigmento. Normalmente, ambos materiales se obtenían exponiendo láminas de plomo al vapor del vinagre y del ácido carbónico. Según el lugar de colocación de las planchas de plomo con respecto a las fuentes productoras de estos vapores, el material blanco resultante - carbonato básico de plomo- cristalizaba en forma de escamas de mayor o de menor tamaño. Las escamas más pequeñas, muy friables, eran raspadas para separarlas de las láminas de plomo, lavadas y amasadas en panes. Por su parte, las escamas de mayor tamaño, constituidas por el carbonato básico de plomo más puro y blanco, eran desprendidas con cuidado y comercializadas en la misma forma en la que se habían recogido. La venta del mejor blanco en forma de laxitas o escamas impedía que fuera adulterado con mezclas de otros materiales de inferior calidad, tales como el blanco de plomo común o la creta (Mérimée, J.-F.-L., op cit., pp. 222-227).

${ }^{53} \mathrm{El}$ término 'vaio', que significa piel de marta o de ardilla, equivale al español 'vero'; v. nota n. ${ }^{\circ} 50$.

54 Armenini, G. B., De' veri precetti della pittura, Rávena, 1587. Ed. Hildesheim, New York, 1971, pp. 110-111. Como en citas anteriores, nos hemos permitido traducir el texto para su mejor comprensión.

${ }_{55}$ Casi dos siglos antes, Cennino Cennini habla de estos dos mismos tipos de pinceles y de su proceso de manufactura (op. cit., pp. 70-72).

${ }_{56}$ Carducho, V., Diálogos de la pintura, Madrid, 1633. Ed. Madrid, 1979, pp. 383-384.
} 
Zuccaro pide, en total, la sorprendente cantidad de 2880 pinceles, 120 docenas de pinceles de ardilla o marta in pena, es decir, con el pelo introducido en el canutillo de una pluma, y otras 120 docenas de pinceles de cerdas fijados, según su tamaño, en pluma o en asta de madera. La elevada cifra de pinceles, todos para trabajar al óleo según se especifica en el pedido, demuestra, sin lugar a dudas, que Zuccaro tenía previsto trabajar con numerosos colaboradores.

\section{APUNTE FINAL}

Por la segunda carta de Zuccaro sabemos que, el 17 de octubre de 1586, los pigmentos azules ya habían llegado y sólo faltaban los pinceles, los cuales al parecer se encontraban ya en camino. En ese mismo documento, el artista nos informa de que meses antes, el 10 de agosto, había ya concluido los dos retablos de las reliquias de la iglesia de San Lorenzo y de que esperaba impaciente el encargo de realizar el retablo mayor (Documento 2).

Paradójicamente, a pesar de los numerosos datos que nos aportan las dos cartas de Zuccaro aquí estudiadas y las muestras de color analizadas, nada, a ciencia cierta, sabemos sobre el uso que tuvieron esos materiales. En conjunto, todos ellos pueden haber sido utilizados en la pintura de los retablos al óleo. A favor de dicha hipótesis tenemos el hecho de que esta técnica se menciona expresamente en la petición de los pinceles, pero hay que tener en cuenta que en el envoltorio que contiene las muestras de azules se lee esmalte "per il fresco». Ciertamente, el esmalte era, por aquel entonces, el pigmento azul más adecuado para su empleo en pintura mural al fresco, dado que era resistente a la cal y que su precio, relativamente barato, permitía su empleo en grandes superficies. No obstante, este pigmento azul también era apropiado para la pintura de retablos. Los tratadistas de la época lo mencionan como un pigmento adecuado para la realización de los fondos y como capa de base en la ejecución de los paños azules más ricos, los cuales eran después recubiertos con una veladura del mejor azul de ultramar ${ }^{57}$.

Finalmente, nos gustaría recordar que, tal como muchos autores han señalado, Zuccaro fue recibido en España con grandes honores y, en cierto modo, las cartas aquí estudiadas lo confirman, ya que según se refleja en ellas el artista pudo disponer de los mejores materiales de la época sin restricciones económicas. Desde este punto de vista, el testimonio más claro es quizás el del gasto que supusieron las sucesivas compras de azul de ultramar, recogidas en éstos y otros documentos conservados en el Archivo General de Simancas ${ }^{58}$ y en el Archivo de la Real Biblioteca de El Escorial.

Es probable que los conocimientos sobre la obra de Zuccaro se acrecienten en un futuro próximo mediante el análisis de muestras tomadas en las pinturas que de este artista se conservan en El Escorial. Ahora y entonces, esperamos que el presente estudio pueda servir para comprender mejor la actividad de este artista en España.

57 De Mayerne da las siguientes instrucciones para lograr un «bello trabajo azul»: "haced con esmalte y blanco de plomo [...] aplicad una capa sobre todo con estos colores. Oscureced con laca. Velad por encima con ultramarino.» (op. cit., p. 114).

58 Deseamos expresar nuestro más sincero agradecimiento a la directora del Archivo General de Simancas, Dña. M. ${ }^{\mathrm{a}}$ Teresa Triguero Rodríguez, quien amablemente nos ha cedido para su estudio unas muestras de los pigmentos conservados en el Archivo. Igualmente, queremos manifestar nuestra gratitud a Dña. María Rosa Saurín, catedrática de Lengua y Literatura Española de la Universidad de Urbino, por su ayuda en la traducción de los documentos, al Dr. Raymond Hourriet, del Laboratoire de Tecnologie des Poudres de la Escuela Politécnica Federal de Lausana, por su desinteresada colaboración en los análisis químicos, y al Dr. Marco Connor, del Departamento de Estructura de la Materia del C.S.I.C., por su ayuda en los estudios de miscroscopía óptica y análisis de imágenes por ordenador. Finalmente, deseamos manifestar nuestro reconocimiento a D. Luis Grau por su apoyo en la busqueda documental. 


\section{DOCUMENTO 1: AGS,Estado,Leg. 1538,fol.364}

Molto Ille ${ }^{\text {re }}{ }^{\text {or }}$ mío

Con questa salutaro VS e gli daro nova del mio / arivo asalvamento iddio laudatto qui in San Lorenzo / il Reale, e furno quindici giorni sono, Io trovai / $\mathrm{S} \mathrm{M}^{\text {ta }}$ a monzon dove fui ben visto, e racolto, e li / sua Mta mi ordino quanto io dovesi fare, con cio mi / vo preparando con un animo grandis ${ }^{\mathrm{mo}}$, per corispondare / anch(')io in qualche parte, a cosi granda et magnifica / fabricha, tuto a gloria e honor di Dio di S M ${ }^{\text {ta }}$ e mia / que fa bisognio Sor mio del Azuro oltra marino / e que ve ne molto pocho, e 1(')opera e molta, questi mini / stri que mi ano ordinato che io facia una lista de / le cose che qui faltano le quali sono in particolare / quanto VS vedra per la inclusa poliza. E per che / fa mistieri che sia uno di la che se ne intenda e cognioscha / la qualita de colori che lo m(i)o disidera, per tanto sira / servi ta VS di far far ricapito di Mons giovan Mario verde / Zotti, il quale e molto intendente di tuto quello che ne fa / bisognio, e qualuque religioso o de la profesione, o sol / fare di quisto azuro oltramarino, et altre volte ne o / av(u)to da lui del belis ${ }^{\text {mo }}$, e quello che lui non avese so, / che sira diligentis ${ }^{\mathrm{mo}}$ a far che $\mathrm{S} \mathrm{M}^{\mathrm{ta}} \mathrm{e} \mathrm{VS}^{\text {or }}$ e io siam serviti,

(fol. 365v) (en el margen: a san barna / ba in cale / longa) / Il Sor Don Cesare Garafa credo lo cognioscha e facilmen / te Vs potra farlo trovare con inviarli la qui inclusa / al quale prego S Sa voglia usare la diligentia che in / cio sira mistieri, e per l(')amicitia che e fra noi mi fido / fara il tuto con molta sincerita et amore, / Io penso che da S Mta gli sara datto ordine di tuto / che bisogniara in torno a cio non mi ocorendo dirli / altro sol che gli resto devotis ${ }^{\mathrm{mo}}$ et Afetis $^{\mathrm{o}}$ ser $^{\mathrm{re}}$ pregan / dola a mio nome salutare il Sre Don Cesare Gara / fa (tachado: a mio nome), con farli parte a S S. $\mathrm{Il}^{\mathrm{me}}$ di questa / che per ora sira comuna non avendo altra comodi / ta, e col pregarli da Dio N S ${ }^{\text {re }}$ ogni prosperita / e contele adibi fo riverenzia e basio la mano di / San Lorenzo il Realle questo primo di (tachado anno e di) / mese e di anno 1586. / Di VS Molto Il ${ }^{\text {me }}$

divos $^{\mathrm{o}}$ et obligatis ${ }^{\mathrm{o}}$ ser $^{\mathrm{re}}$

E quanto prima VS ci potra / inviare detti colori (tachado: sira) / ci siran piu comodi al bisognio fede ${ }^{\mathrm{co}}$ Zucharo

Por detrás de la carta aparecen dos inscripciones:

1) La destinación de la carta, con la misma letra de ésta: $\mathrm{Al}$ molto $\mathrm{Ill}^{\text {re }} \mathrm{s}^{\text {re re }}$ per o SS / Il Sg ${ }^{\text {or }}$...Salazaro Segre $^{\mathrm{o}}$ del Imbasiate di S $\mathrm{M}^{\text {ta }}$ Catolica / in Venetia

2) Otra en español, con diferente letra:

Federico Zucaro / respondiose ya a 7 de junio de 1587 / y recibida este dia

AGS, Estado, Leg. 1538, fol. 365.:

Colori per pigliarsi in Venetia per $\mathrm{SM}^{\text {ta }}$

Azuro oltra marino del piu bello e carico / di colore da venti e venticinque schudi / l(')oncia de la mostra che si manda li / bre una L 1

Altro azuro oltra marino bello da v10 e / 12 l(')oncia libre una L 1

Altro azuro oltra marino piu baso da / 3 e quatro schudi l(')oncia libre dua L 2

Ceneracio di oltra marino da mezo scu / do e un schudo l(')oncia libre sei L 6

Smalto da Morano del piu schuro, / e carico di colore conforme alla mostra libre cinquanta L 50

Biacha della piu bella libre trecento L 300

Penelli di varo in pena a olio picioli / mezani e piu grandi dozene quaren/ta per sorta in tuti doz de $^{\text {ne }} 120$

Altri penelli di setole in pena e in asta / da lavorare a olio di picoli di me / zani e di piu grosi dozene quaranta / per sorte in tuto doz ${ }^{\text {ne }} 120$ 
DOCUMENTO 2: AGS, Estado, Leg. 1538, fol. 366.

$$
\mathrm{Ill}^{\text {re }} \mathrm{s}^{\mathrm{re}}
$$

Ricevi la sua gratis ${ }^{\text {ma }}$ parechi giorni sono dove avisava VS / l(')invio delle azuri ultramarini e la diligen-

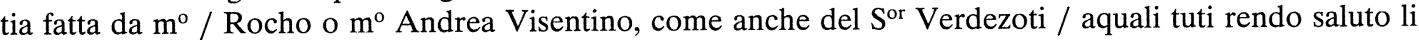
azuri sono arivati, aspetamo / i penelli, che anchora non sono arrivati, e ne avemo care / stia, per non cio sare qua ricapito da farne, ma se intende che / sono per camino come anche VS mi avisa, / Piacera a VS favorirmi de fare ricapitare le qui incluse / al $\mathrm{S}^{\text {or }}$ Patriarcha Grimani sele costi in Venetia o a sua / casa, parimente al $S^{\text {or }}$ giovan mario Verde Zoti sole / costi in Venetia o al suo benefitio, sel Verde Zoti non fose / in Venetia potra VS inviare la letera aperta, al $S^{\text {or }}$ Paulo / Veronese o al S ${ }^{\text {or }}$ Alesandro Vitoria, aquello che gli e / piu comodo, che gustarano di alchuni particolari che / gli scrivo di questa gran fabrica, e belis ${ }^{\text {mo }}$ luogo di / Arangioes e Toledo.

A VS Ils ${ }^{\text {ma }}$ non gli diro altro per ora sol che io atendo con ogni mia / industria e diligentia al servitio di SM ${ }^{\text {ta }}$, e per averli aquesto San Lorenzo (tachado: prosimo pasato) e per la beneditione di questa / gliesa che fu alli 10 di Agosto prosimo pasato datto fini / to le doi altari delle reliquie con molto gusto e piacere, / e innaspetatamente in pochis ${ }^{\mathrm{mo}}$ tempo, fu tanto magiore il / gusto di SM${ }^{\text {ta }}$ che alla partita sua di qui l(')altra matina / per madril, mi dono mille schudi d(')oro, di moneda, la / liberalita e dignita di SM ${ }^{\text {ta }}$, a gli animi, et acresie le / forze altrui, che io non mi son stancare a far cosa che gli posa / esare grata, Io atendo ora al Retabolo magiore e prochu / ro vincer me stesso, la mi favorira basiar le mane / a mio nome al $\mathrm{Ill}^{\mathrm{mo}} \mathrm{S}^{\text {or }}$ Don Cesare garafa che esendo

\section{(fol. 366v)}

egli statto particolare instromento a trovarmi di mia casa / e mie comodita, e pigliar questa servita gli preservo 1(')obligo che io devo et a VS Ill ${ }^{\mathrm{ma}}$ (?), che Iddio NS ${ }^{\text {re }}$ doni / a VS ogni (?) felicita, basio le mane di San Lorenzo Il Reale questo di 17 ottobre 1586

Di VS molto Ill ${ }^{\text {re }}$

Il vos ${ }^{\circ} \mathrm{Ser}^{\mathrm{re}}$

Fede ${ }^{\text {co }}$ Zucharo

Aquí también hay dos inscripciones por la parte posterior de la carta: 1) La destinación de la carta, con la misma letra y tinta que el resto de la carta: Al Ille $^{\mathrm{re}} \mathrm{Sig}^{\mathrm{re}}$ mio Oss ${ }^{\circ} \mathrm{Il} \mathrm{Sig}^{\text {or }}$ Cristofa / ro di Salazaro, segre ${ }^{\mathrm{o}}$ di S $\mathrm{M}^{\mathrm{ta}} /$ Catolica / a Venetia

2) Una anotación con letra diferente a la inscripción anterior: Risponsa a 20 febraio 1587

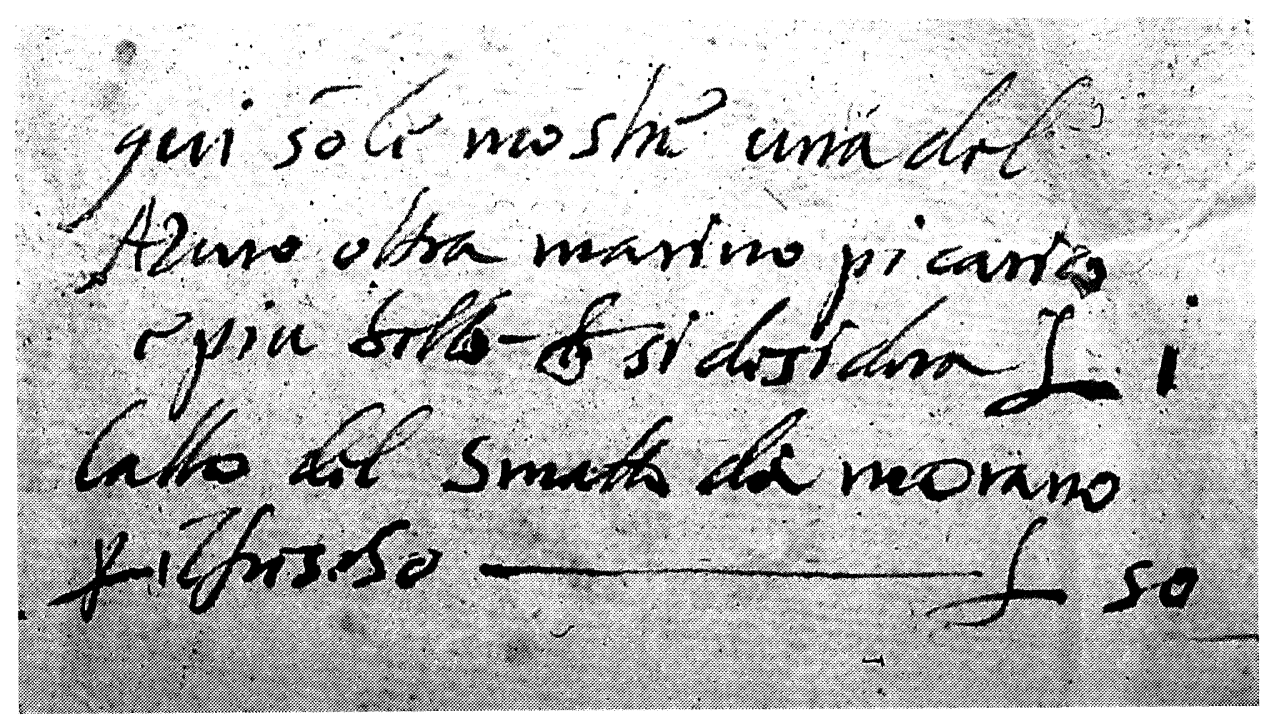

Fig. 1. Inscripción que acompañaba a las muestras de pigmentos. Archivo general de Simancas. 